\title{
Abriendo los Partidos Políticos: acceso a la información tras la Reforma a la Ley Orgánica Constitucional de Partidos Políticos
}

\author{
Pablo Contreras Vásquez* \\ Leonardo Ortiz**
}

\begin{abstract}
ReSUMeN
El artículo analiza la reforma a la Ley Orgánica Constitucional de los Partidos Políticos en materia de derecho de acceso a la información partidaria, dando cuenta de la incorporación de este derecho como un derecho de titularidad de los afiliados a un partido. Al constituir una materia reservada a la regulación interna de los partidos políticos, se investigan todos los partidos legalmente constituidos para determinar si cuentan o no con reglas que habiliten el ejercicio del derecho. La investigación constata que solamente una minoría de partidos cuentan con normativas que van más allá de la regulación legal. Sin embargo, se observan importantes omisiones a nivel de la regulación partidaria. El texto concluye que la ausencia de una regulación interna adecuada para el ejercicio del derecho puede obstaculizar el acceso a la información de los partidos por parte de sus afiliados.
\end{abstract}

Acceso a la información; transparencia; partidos políticos

\section{Opening Political Parties: \\ Freedom of Information after the Amendment to the Organic Constitutional Law of Political Parties}

\begin{abstract}
The paper examines the amendment to the Organic Constitutional Law of Political Parties regarding the inclusion of freedom of information as a right of which party members are entitled.
\end{abstract}

* Licenciado en Ciencias Jurídicas y Sociales, Universidad Alberto Hurtado, Chile. Doctor en Derecho, Northwestern University, Estados Unidos. Profesor de Derecho Constitucional y Director del Centro de Regulación y Consumo de la Universidad Autónoma de Chile. Correo electrónico: pablo.contreras.v@gmail.com

** Licenciado en Ciencias Jurídicas y Sociales, Universidad Alberto Hurtado, Chile. Ayudante senior del Departamento de Investigación de la Facultad de Derecho de la Universidad Alberto Hurtado. Correo electrónico:

Artículo recibido el 15.3.2019 y aceptado para su publicación el 9.9.2019. 
As it is a matter reserved for the internal regulation of political parties, all legally constituted parties are researched so as to determine whether or not they have rules that enable exercising of the right. The research shows that only a minority of political parties have regulations that go beyond the law. However, important omissions are observed at the level of parties' regulations. The paper concludes that the absence of adequate internal regulation for the exercise of the right may hinder access to party information by its members.

Freedom of information; transparency; political parties

\section{INTRODUCCIÓN}

$\mathrm{L}$ a reforma a los partidos políticos implicó un cambio del estatuto de los partidos, pasando de meras asociaciones voluntarias a personas jurídicas de derecho público, las que pasarían a tener financiamiento público ${ }^{1}$. La contrapartida, desde el punto de vista de la rendición de cuentas, fue el establecimiento de deberes de transparencia, entre otras exigencias ${ }^{2}$. En general, no es posible identificar una vasta doctrina iuspublicista que analice materias referidas a partidos políticos, salvo importantes excepciones ${ }^{3}$. En este sentido, las profundas reformas al sistema político que se impulsaron en el último gobierno merecen especial atención para su intelección dogmática de cara a su aplicación.

La inclusión de obligaciones de transparencia amplió el tipo de sujetos obligados en materia de acceso a la información y deberes de publicidad. En efecto, el sistema que estableció la Ley 20.285, sobre acceso a la información pública, optó por circunscribirse a órganos estatales ${ }^{4}$. Esto supuso la exclusión de otras categorías de entidades que desarrollan funciones públicas o brindan servicios públicos ${ }^{5}$. Si bien existe cierta jurisprudencia acotada del Consejo para la Transparencia -ratificada por los tribunales superiores de justicia- que ha ampliado la aplicación de la ley a entidades privadas, lo cierto es que se trata de un régimen estrictamente excepcional ${ }^{6}$. En este caso, el legislador modificó expresa y directamente la Ley Orgánica Constitucional de Partidos Políticos

\footnotetext{
${ }^{1}$ Jordán y Figueroa, 2017; Contreras, 2018. En general, véase Osorio, 2018.

2 Jordán y Figueroa, 2017, p. 41.

${ }^{3}$ Durante la vigencia de la Constitución de 1925, véase AmunÁtegui, 1952 y Silva Bascuñán, 1963.
} Bajo el marco de la Constitución de 1980, véase García, 1988; Barros, 1984; Nogueira, 2005; Ribera, 2008; Díaz y Sierra, 2012; Santibáñez, 2014; Silva Gallinato, 2016. Tras la Ley 20.915, 2016; véase a García, 2017; Jordán y Figueroa, 2017; Osorio, 2018.

${ }^{4}$ Ferrada, 2010.

5 Soto Kloss, 1986; Rojas, 2014.

${ }^{6}$ El ejemplo más evidente son las corporaciones municipales, donde los tribunales superiores de justicia han ratificado sistemáticamente las decisiones del Consejo para la Transparencia. Véase, a título ejemplar:

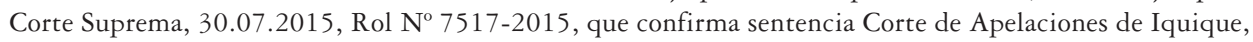
01.06.2015, Rol No 195-2015; Corte de Apelaciones de Valparaíso, 14.06.2010, Rol No 2361-2009; Corte de Apelaciones de Valparaíso, 29.06.2010, Rol N 294-2010; Corte de Apelaciones de Santiago, 10.08.2010, Rol No 132-2010; Corte de Apelaciones de Puerto Montt, 27.01.2011, Rol No 395-2010; Corte de Apelaciones de Puerto Montt, Rol No 906-2011, 13.02.2012. 
(en adelante, LOCPP) para crear un estatuto de transparencia ad hoc para los partidos políticos. A pesar de que no son órganos del Estado a los que se les podría extender naturalmente el principio de publicidad constitucional ${ }^{7}$, el legislador decidió asignar deberes especiales de acceso a la información y transparencia activa a los partidos.

Este artículo aborda la regulación del derecho de acceso al interior de los partidos políticos y deja fuera la revisión de otras obligaciones de transparencia y rendición de cuentas que fueron creadas por la ley ${ }^{8}$. Como el derecho de acceso fue creado dentro del catálogo de derechos y deberes de los afiliados a los partidos, el rol regulatorio de estos entes es central. En efecto, el mismo legislador encomienda a cada partido la obligación de detallar y especificar los derechos de los afiliados. Por ello, la realización del derecho de acceso dependerá, en buena medida, de la actividad normativa de los partidos y del grado de intensidad regulatoria que habilite el ejercicio del derecho, fije el procedimiento de acceso y permita impugnar omisiones de entrega o denegaciones de acceso a la información. Desde una perspectiva más amplia, el estudio de la remisión regulatoria que hace el legislador a cada partido -confiando el desarrollo del derecho de acceso de sus afiliados- puede brindar luces sobre si esta técnica legislativa alcanza un óptimo adecuado entre la flexibilidad que respeta la autonomía partidaria y la necesidad de proteger ciertos derechos o intereses que son relevantes para la comunidad política.

Para ello, el texto adopta la siguiente estructura. Primero se analiza la reforma a la LOCPP en materia de derecho de acceso a la información, dando cuenta de la incorporación de este derecho y sus concordancias normativas (II). Luego se examina la reglamentación interna que los partidos han dictado para disciplinar el ejercicio del derecho y para darle un procedimiento de acceso a la información partidaria (III). El texto concluye destacando los principales avances y déficits que se mantienen en materia de acceso a la información partidaria (IV).

\section{La reforma a la Ley Orgánica Constitucional de Partidos Políticos EN MATERIA DE ACCESO A LA INFORMACIÓN}

La Ley 20.915 que fortalece el carácter público y democrático de los partidos políticos y facilita su modernización, modificó el catálogo de derechos de los afiliados a los partidos políticos, obligando a que los partidos fijen en los estatutos una "especificación detallada" de los derechos y deberes que les corresponden (art. 20 LOCPP). La reforma incluyó un nuevo derecho de "[s]olicitar y recibir información que no sea reservada o secreta, en virtud de lo dispuesto en el artículo 8 de la Constitución o cuya publicidad, comunicación o conocimiento no afecte el debido cumplimiento de las funciones del partido. Los afiliados podrán impugnar ante el tribunal supremo, cuya resolución será

\footnotetext{
${ }^{7}$ Osorio, 2018, p. 134.

${ }^{8}$ Para revisar los demás cambios en materia del estatuto de transparencia de partidos políticos, véase Contreras, 2018; Jordán y Figueroa, 2017; Osorio, 2018, pp. 201-203.
} 
reclamable ante el Servicio Electoral frente a la negativa del partido de entregar dicha información. [...]”"

Mediante la modificación legal, se incorpora una regla especial que regula el ejercicio del derecho de acceso a información pública respecto de un órgano que no es estatal ni ha sido creado por el Estado para el cumplimiento de funciones públicas. Esto implica ampliar la transparencia y los deberes asociados a este derecho a entes no estatales que desempeñan un importante rol dentro del funcionamiento de una sociedad democráti$\mathrm{ca}^{9}$. El alcance del derecho y el procedimiento para acceder a la información debiese ser desarrollado por cada partido en sus estatutos ${ }^{10}$ aunque, como veremos, la intensidad regulatoria de aquello es sumamente dispar.

El acceso a la información del partido podría ser reconducido al régimen general del derecho de acceso a la información pública, pero con una regulación especial al margen de la Ley de Transparencia. En este caso, la ley reserva el ejercicio del derecho a los afiliados del partido, como titulares exclusivos del mismo ${ }^{11}$. Ello no impedirá, como revisaremos, que los mismos partidos se autorregulen, ampliando los sujetos activos del derecho ${ }^{12}$ o innoven en otros supuestos que la ley no prevé. Por consiguiente, el partido político es responsable de responder la solicitud de acceso a la información. A diferencia del régimen general de la Ley de Transparencia, la LOCPP no fija el órgano u ente responsable de responder las solicitudes de acceso a la información, cuestión que quedará a la regulación de cada partido.

El afiliado tiene derecho a solicitar y recibir información del partido. El mismo artículo da derecho a solicitar "la rendición de balances y cuentas que sus dirigentes se encuentren obligados a presentar durante su gestión”. En la historia de la ley (HDL) se despejaron algunas dudas acerca del alcance de la solicitud. Por ejemplo, se entendió que se podrá solicitar información del partido y no de la gestión parlamentaria de diputados o senadores que pertenezcan a dicho partido ${ }^{13}$. Si bien no se mencionaron otros cargos de representación popular, el criterio podría ser extensible fácilmente por analogía.

Como se ha afirmado, el derecho creado tiene por objeto controlar la actividad partidaria y elevar los estándares de rendición de cuentas internas ${ }^{14}$. Por esta razón, restringe la regla de titularidad y delimita el objeto a materias propias del partido. En cuanto a los límites del derecho, la ley se remite al artículo $8^{\circ}$ de la Constitución para hacer aplicable las cuatro causales genéricas de reserva o secreto de información: afectar el debido cumplimiento de las funciones del órgano, afectar los derechos de las personas,

9 Por todos, Verdugo y García, 1992, pp. 65-72; Aldunate, 2009, pp. 273-27; Pérez Royo, 2007, pp. 565-569; OÑATE, 2005, pp. 261-262.

${ }^{10}$ Durante la tramitación legislativa se alertó respecto de la falta de regulación legal del procedimiento de acceso. Véase Biblioteca del Congreso Nacional, 2018, p. 72.

${ }^{11}$ Lo que contrasta con la titularidad universal del derecho de acceso a la información pública. De la titularidad de derechos fundamentales, véase Aldunate, 2008, pp. 147 y ss.; Contreras, 2017, pp. 119-160.

12 Véase, infra III.2.c).

13 Biblioteca del Congreso Nacional, 2018, pp. 428-429.

${ }^{14}$ Contreras, 2018. 
afectar la seguridad nacional o afectar el interés nacional ${ }^{15}$. Adicionalmente, la ley regula una causal especial: se puede denegar el acceso cuando su "publicidad, comunicación o conocimiento no afecte el debido cumplimiento de las funciones del partido". En la historia de la Ley 20.915 se reiteró constantemente el ejemplo de reserva de información "particularmente en el contexto de una estrategia electoral"16 o, más en general, "información estratégica, tal como discusiones sobre posturas electorales, posiciones en materias de políticas públicas" 17 . La remisión al artículo $8^{\circ}$ ha sido criticada por parte de la doctrina. Osorio estima que es "poco feliz", ya que "aun cuando los partidos políticos son personas jurídicas de derecho público, no son un órgano del Estado, por lo que la aplicación del artículo 8 no es posible realizarla"18. El alcance de la remisión, al parecer para Osorio, está en cuestionamiento en función del tipo de sujeto obligado por el principio de publicidad. En este punto, Osorio tiene razón y existe un antecedente en la historia fidedigna de la norma que lo respalda ${ }^{19}$. En efecto, los partidos políticos no pueden ser tratados como si fueran órganos estatales, pese a su amplificación en la última reforma a la LOCPP. Pero el objetivo deliberado del legislador fue adaptar la aplicación del artículo 8 a las normas de los partidos políticos. Explícitamente, el senador Harboe planteó lo siguiente: "la norma propuesta introduce una causal de reserva específica respecto de la información que los partidos políticos deben entregar a sus afiliados, lo que debe considerar el tenor de los dispuesto en el inciso segundo del artículo $8^{\circ}$ de la Constitución Política de la República, aun cuando se trata de una norma aplicable a los órganos del Estado"20. Por tanto, se quería "considerar las específicas hipótesis de restricción que, respecto del principio general de acceso a la información, consagra dicha disposición constitucional" 21 .

Por nuestra parte, una posibilidad es que el artículo 8 brinde mayores luces para la delimitación del objeto del derecho, al abarcar actos o resoluciones partidarias, así como sus fundamentos o procedimientos que utilicen. Es decir, entendiendo que no es posible aplicar automáticamente el artículo $8^{\circ}$ de la Constitución en función del sujeto obligado, sí es posible una interpretación que brinde un sentido útil a la remisión que hace el art. 20 LOCPP en razón de los otros elementos de la norma constitucional, como el tipo de objeto al que se le aplica la regla de acceso partidario (actos o resoluciones, sus fundamentos o procedimientos "partidarios"). En este sentido, la remisión permitiría

${ }^{15}$ Sobre el artículo $8^{\circ}$ de la Constitución, véase en general Hernández, 2006; Fernández, 2005; Ruiz-Tagle, 2006; Fernández, 2007.

${ }^{16}$ Biblioteca del Congreso Nacional, 2018, p. 326.

17 Biblioteca del Congreso Nacional, 2018, p. 73.

18 OSORIO, 2018, p. 134.

${ }^{19}$ Biblioteca del Congreso Nacional, 2018, p. 326. La abogada María Jaraquemada, representante de la fundación "Espacio Público" afirmó lo siguiente: "las normas sobre derecho de acceso a la información pública son aplicables a los órganos del Estado, por lo que no operan respecto de los partidos políticos”.

${ }^{20}$ Biblioteca del Congreso Nacional, 2018, p. 327.

21 Biblioteca del Congreso Nacional, 2018, p. 327. 
especificar el objeto del derecho genérico de "solicitar y recibir información” que ha sido creado.

Por otro lado, la remisión del art. 10 LOCPP también permitiría fundar un régimen de reserva o secreto de información en concordancia con las causales constitucionales del artículo 8. Osorio entiende que la "interpretación correcta, de dichas normas, consiste en sostener que los actos que el partido tendrá derecho a no transparentar, será cuando la publicidad de dicha información afecte el debido cumplimiento de las funciones del partido o los derechos de los afiliados" 22 . Pero ello supone excluir a priori otras dos posibles causales de reserva o secreto: seguridad de la Nación e interés nacional. Si bien es más remota la posibilidad de que el partido disponga información relativa a ella, no es descartable que, tanto partidos oficialistas como opositores, puedan acceder y mantener información cuya divulgación afecte dichos bienes constitucionales. Para concluir este punto, si bien compartimos con Osorio que el artículo $8^{\circ}$ de la Constitución tiene un ámbito de aplicación subjetivo reservado a los órganos del Estado, es necesario darle un sentido útil a la remisión que ha efectuado el legislador en el artículo 20 LOCPP. En este sentido, la remisión podría entenderse como una forma de especificar el objeto del derecho de acceso -actos y resoluciones partidarias y sus fundamentos o procedimientos- y complementar el cuadro de causales de reserva o secreto -incluyendo las cuatro causales de reserva de información que establece la Constitución-. En cualquier caso, así como se discutió durante la tramitación legislativa, con la norma se buscó cierta "holgura" y que la publicidad no afectare "el normal desenvolvimiento del partido"; por ello, es el partido el que califica la reserva o secreto de la información ${ }^{23}$, sin perjuicio de los controles que la misma norma establece.

Finalmente, la LOCPP estableció un procedimiento de reclamación por omisiones o denegaciones de acceso a la información. Para ello, el afiliado debe impugnar la decisión ante el órgano contralor o tribunal supremo del partido. A su vez, la decisión del dicho ente es reclamable ante el Servicio Electoral (en adelante, Servel). La tramitación interna de la impugnación, nuevamente, dependerá de la intensidad regulatoria de los estatutos de cada partido en esta materia. La garantía del derecho de acceso a la información en partidos políticos estatuye al Servel como órgano administrativo autónomo revisor de los reclamos por parte de afiliados a partidos, por denegación o no entrega de información. Ello necesariamente supondrá un desafío en el desarrollo de una jurisprudencia administrativa que dialogue con los estándares fijados por el Consejo para la Transparencia y los tribunales de justicia en la aplicación de las causales de secreto o reserva de la información. Sin embargo, a la fecha de cierre del presente estudio, y en virtud de una solicitud de acceso a la información enviada a Servel, dicho organismo declara no haber conocido impugnaciones por esta materia ${ }^{24}$.

${ }^{22}$ OSORIO, 2018, p. 134.

23 Biblioteca del Congreso Nacional, 2018, pp. 180-181; 326.

${ }^{24}$ Servicio Electoral, 2018, Oficio Ordinario No 3593, de 5 de octubre de 2018. La respuesta del Servel a la respectiva solicitud de información, puede ser consultada en el siguiente sitio web: https://www. dropbox.com/sh/cqbghlr30p8dto7/AACphmToOIudwGsH50jy-0Cja?dl=0 [fecha de consulta: 27.02.2019]. 
A continuación se analiza la forma en que los partidos han abordado la regulación del derecho de acceso y la densidad regulatoria del ejercicio y procedimiento del derecho.

\section{EL PROCEDIMIENTO DE ACCESO A LA INFORMACIÓN PÚBLICA EN LA REGULACIÓN DE LOS PARTIDOS POLÍTICOS}

Como se revisó en la sección anterior, la ley no previó una regulación del procedimiento de acceso a la información en partidos políticos. En este caso, atendido a su carácter especial, la regulación de las condiciones de ejercicio del derecho de acceso quedará sujeto a la autonomía normativa de cada partido. Lo anterior podría traer como consecuencia que este derecho se convierta en "letra muerta", al no existir regulación procedimental mínima que permita el ejercicio de este derecho en la práctica, ya que los estatutos del partido podrían omitir reglas de plazo, intervención de terceros, responsabilidad de respuesta o requisitos de impugnación, entre otras materias.

En esta sección se examina empíricamente el actual panorama normativo interno de cada partido político, compuesto por estatutos, reglamentos, protocolos, circulares o cualquier otro tipo de regulación; y junto con ello -en caso de existir regulación- se analiza cualitativamente la manera en que cada partido regula el procedimiento del derecho de acceso a la información partidaria, en términos de que este habilite eficazmente el ejercicio de aquel por parte de sus afiliados.

\section{Informalidad regulatoria del derecho de acceso por parte de los partidos}

Para efectos de revisar la normativa partidaria respecto de la regulación del derecho de acceso a la información de sus afiliados, se examinaron las fuentes primarias de los partidos, conforme con la siguiente estructura metodológica. En primer lugar se identificaron los partidos políticos legalmente constituidos al 28 de febrero de 2019. Enseguida se verificó si cada uno de aquellos partidos políticos contaban o no con la existencia de un sitio web que permitiera la consulta de la normativa interna que por mandato legal han de tener publicada, para -en el caso de contar con regulación-analizar la manera en que regulan el derecho de acceso. Luego, respecto de aquellos partidos que no contaban con sitio web o que, de poseerlo, no tuvieran su normativa interna publicada, se efectuó una solicitud de acceso a la información pública dirigida al Servel, con el fin de obtener acceso al expediente administrativo de constitución de partido y poder examinar allí, de forma directa, la normativa interna faltante. Finalmente se intentó establecer una comunicación particular con cada uno de los partidos políticos a modo de obtener información que pudiere no estar publicada o que, de estarlo, se precisase su sentido y alcance. Los resultados arrojados por esta constatación empírica se detallarán en las líneas que siguen. 
A base de la información disponible en el sitio web del Servel, se determinó que existen 20 partidos políticos constituidos a la fecha de efectuada dicha consulta ${ }^{25}$, en conformidad con lo dispuesto por la LOCPP.

El Servel, junto con tener a disposición permanente del público la lista actualizada de partidos políticos legalmente constituidos, sitúa para cada uno de ellos una ficha con información básica y elemental, según hayan informado estos de manera oficial al Servicio $^{26}$. A partir de aquello, $80 \%$ del total de partidos políticos legalmente constituidos - 16 de 20- poseen un sitio web informado de manera oficial al Servel. En lo que respecta al otro $20 \%, 2$ de ellos poseen sitio web, pero no informado de manera oficial ${ }^{27}$; mientras que los otros 2 restantes derechamente carecen de sitio web alguno ${ }^{28}-10 \%$ del total de partidos políticos constituidos-.

Con la Ley 20.915, los partidos están obligados a mantener sitios web, al menos para efectos de proporcionar la información a que están obligados en razón de sus deberes de transparencia activa (art. 49 LOCPP). La LOCPP dispone que los derechos de los afiliados a los partidos políticos deberán estar contenidos en sus estatutos, dentro de los que necesariamente se incluirán, el derecho de acceso a la información y los procedimientos que lo regulen (art. $20 \mathrm{~N}^{\circ}$ 1, letra f) LOCPP). Asimismo, existe un deber de transparencia del marco normativo aplicable del partido político que deberá estar "a disposición permanente del público, a través de sus sitios electrónicos, en forma completa, actualizada [...]” (art. 49, letra a) LOCPP). De lo anterior, es posible colegir que aquellos partidos políticos que no cuentan con un sitio web están incumpliendo los deberes de transparencia activa e impiden acceder al público general al detalle del marco regulatorio en que pueda estar contenido el derecho de acceso a la información de sus afiliados.

Teniendo como base una primera aproximación empírica a partir de la revisión del Portal de Transparencia del Estado y de los sitios web de aquellos partidos políticos que cuentan con uno, ya sea informado o no informado oficialmente al Servel, efectuamos un levantamiento de cada normativa interna publicada por estos, en búsqueda de algún tipo de regulación al procedimiento de ejercicio del derecho de acceso a la información. Pudimos determinar que $22 \%$ de partidos que cuentan con sitio web -4 de $18-$ no tendrían ningún tipo de regulación del derecho de acceso a la información por parte de sus afiliados ${ }^{29}$. Sumado a aquellos partidos políticos que carecen de sitio web, podemos

${ }^{25}$ Servicio Electoral, 2018. Los partidos políticos legalmente constituidos a la fecha de consulta son: Renovación Nacional (RN), Partido Demócrata Cristiano (PDC), Partido Por la Democracia (PPD), Unión Demócrata Independiente (UDI), Partido Socialista (PS), Partido Radical Socialdemócrata (PRS), Partido Comunista (PC), Partido Humanista (PH), Andha Chile (ACh), Evolución Política (Evópoli), Revolución Democrática (RD), Federación Regionalista Verde Social (FRVS), Izquierda Anticapitalista de los Trabajadores (IAT), País Progresista (PRO), Ciudadanos, Partido Regionalista Independiente Demócrata (PRID), Partido Ecologista Verde (PEV), Poder Ciudadano, Partido Igualdad (PI) y Más Izquierda Ciudadana (MIC).

26 Servicio Electoral, 2018.

${ }^{27}$ Este es el caso de los partidos políticos Federación Regionalista Verde Social y Partido País Progresista.

${ }^{28}$ Este es el caso de los partidos políticos Izquierda Anticapitalista de los Trabajadores y Más Izquierda Ciudadana.

29 Tal es el caso de Partido Igualdad, Partido Humanista, Andha Chile y Ciudadanos. 
concluir que, a primera vista, $30 \%$ de los partidos legalmente constituidos a la fecha no contarían con algún tipo de regulación del derecho de acceso a la información. En otros términos, bajo esta primera revisión, únicamente el $70 \%$ de los partidos políticos legalmente constituidos -esto es, 14 de 20 partidos- tendrían algún tipo de regulación del derecho de acceso a la información por parte de sus afiliados.

Tres partidos políticos no tenían publicados sus estatutos en su sitio web o, derechamente, carecían de una página en línea ("Izquierda Anticapitalista de los Trabajadores", "Partido Ciudadanos" y "Más Izquierda Ciudadana”). Para lograr la revisión cabal de la regulación del derecho de acceso en los partidos políticos, se efectuó una solicitud de acceso a la información pública al Servel, requiriendo la resolución de constitución y su respectivo expediente administrativo -incluyendo los estatutos que fundamentan tal decisión- de estos partidos. De la información recibida por Servel ${ }^{30}$, se pudo determinar que dichos partidos sí contaban con algún tipo de regulación del derecho en sus estatutos.

La ausencia de la información disponible en línea supone una infracción a los deberes de transparencia activa, respecto de estos partidos. Sin perjuicio de lo anterior, bajo estos nuevos antecedentes, la situación regulatoria del derecho de acceso en términos cuantitativos cambió. En este sentido, de los 18 partidos políticos que cuentan con algún sitio web, ya sea informado o no informado de manera oficial al Servel, 15 partidos cuentan algún tipo de regulación del derecho ${ }^{31}$. Es decir, el $17 \%$ de los partidos que cuentan con sitio web no tienen regulación alguna del derecho de acceso. Asimismo, los otros 2 partidos políticos que no cuentan con sitio web alguno, según información proporcionada por el Servel, sí regulan el derecho a la información partidaria ${ }^{32}$, por lo que es posible determinar que de 20 partidos políticos legalmente constituidos, 17 de ellos (85\% del total) cuenta con algún tipo de regulación del derecho de acceso a la información por parte de sus afiliados ${ }^{33}$.

La situación de los partidos que regulan de algún modo el derecho de acceso a la información es diferente según el caso. Solo 15 partidos contienen algún tipo de regulación en sus estatutos partidarios $(88 \%)^{34} ; 1$ partido político contiene algún tipo de regulación en el reglamento orgánico $(67 \%)^{35} ; 1$ partido político cuenta con un

30 Servicio Electoral, 2018, Oficio Ordinario No 4019, de 8 de noviembre de 2018. La respuesta del Servel a la respectiva solicitud de información, puede ser consultada en el siguiente sitio web: https://www. dropbox.com/sh/cqbghlr30p8dto7/AACphmToOIudwGsH50jy-0Cja?dl=0 [fecha de consulta: 27.02.201919].

${ }^{31}$ En este sentido, el Partido Ciudadanos, que no tenía publicado sus estatutos en su sitio web, sí cuenta con algún tipo de regulación al derecho a la información partidaria, conforme a información entregada por Servel.

32 Caso de los partidos Más Izquierda Ciudadana e Izquierda Anticapitalista de los Trabajadores.

${ }^{33}$ En rigor, los partidos políticos que no cuentan con ningún tipo de regulación del derecho de acceso a la información partidaria son: Partido Igualdad, Partido Humanista y Partido Andha Chile.

${ }^{34}$ En esta situación se encuentran: UDI, Evópoli, Federación Regionalista Verde, Partido País Progresista, Partido Regionalista Independiente Demócrata, PPD, RN, PC, PS, Partido Poder Ciudadano, PDC, Partido Ecologista Verde, Partido Ciudadanos, Más Izquierda Ciudadana y Partido Anticapitalista de los Trabajadores.

${ }^{35}$ Es el caso de Revolución Democrática. 
reglamento especial de derecho de acceso a la información $(6 \%)^{36}$; y, finalmente, 1 partido político cuenta, además de su regulación normativa, con una ficha o formulario de solicitud de acceso a la información (SAI) a disposición de sus afiliados (6\%), similar al que disponen los órganos del Estado en sus sitios webs para el cumplimiento de la Ley de Transparencia ${ }^{37}$. De lo anterior se puede concluir que si bien el legislador mandató a los partidos políticos a regular los derechos y deberes de los militantes en sus estatutos -según dispone el artículo $20 \mathrm{~N}^{\circ} 1$ LOCPP-, los partidos lo han hecho no solo en dicho cuerpo normativo sino también en otro tipo de normativas internas. En este punto, la práctica partidaria ha entendido en sentido amplio el tipo de norma interna que regule los derechos de los afiliados ${ }^{38}$.

Finalmente se procedió a consultar de manera particular a cada partido político legalmente constituido, por la información que obrara en su poder acerca de documentos y antecedentes -ya sea contenido en estatutos, reglamentos, protocolos, circulares o cualquier otro soporte- que contenga el procedimiento de ejercicio del derecho de acceso a la información por parte de sus afiliados, con el objeto de verificar y contrastar la información completa referida a la regulación del derecho de acceso, tanto aquella informada en los sitios web como aquella que nos remitieran directamente ${ }^{39}$.

Mediante dicha solicitud se obtuvo respuesta únicamente de 5 de los 20 partidos políticos legalmente constituidos ${ }^{40}$. De aquellas respuestas recibidas, solo 2 partidos brindaron información adicional a la ya recopilada ${ }^{41}$. En cuanto al resto, una parte de los partidos políticos confundieron la información solicitada con la dispuesta por el artículo 49 LOCPP -esto es, la información que es parte de los deberes de transparencia activa-; o con aquella establecida por la Ley de Transparencia ${ }^{42}$. La otra parte de los partidos se limitaron a indicar que se debía revisar la información publicada en los portales de transparencia activa ${ }^{43}$.

${ }^{36}$ Es el caso del Partido Radical Socialdemócrata que será analizado en detalle más adelante.

37 Es el caso del Partido Comunista.

38 Sin perjuicio de ello, el marco normativo debe ser publicado. Véase Instrucción General N 12 del Consejo para la Transparencia, sobre transparencia activa de partidos políticos, de 28 de septiembre de 2016. [Disponible en: https://www.consejotransparencia.cl/wp-content/uploads/instruccion/2018/02/ ig_12_versi_n_web.pdf] [fecha de consulta: 09.10.2018].

39 Las comunicaciones con los partidos políticos pueden ser consultadas en el siguiente sitio web: https://www.dropbox.com/sh/cqbghlr30p8dto7/AACphmToOIudwGsH50jy-0Cja?dl=0 [fecha de consulta: 27.02.2019].

${ }^{40}$ Es el caso de los siguientes partidos: PDC, PPD, Evópoli, Partido Ecologista Verde y RD.

${ }^{41}$ El PDC señaló que la solicitud de información por parte de sus afiliados debe ser dirigida al Secretario Nacional mediante correo electrónico o por carta. RD, por su parte, indicó que existe nueva regulación en estatutos, en actual estado de revisión por el Servel.

${ }^{42}$ Evópoli respondió que dicha información es parte de " $[. .$.$] todo lo que contempla la norma de$ difusión y transparencia que está en la ley de partidos políticos, y lo que tiene que ver con publicidad de gastos e ingresos electorales, que está en la ley de gasto electoral”. Finalmente, el Partido Ecologista Verde, respondió que "los partidos políticos están sometidos a la Ley de Transparencia, es mediante ese mecanismo por el cual se rigen”.

43 Este es el caso del PPD. 
A base del levantamiento efectuado, el $85 \%$ de los partidos sí cuenta con alguna regulación respecto del derecho de acceso de los afiliados. Sin embargo, no basta constatar la existencia de esta información, sino que fue necesario abocarse a evaluar la suficiencia e intensidad regulatoria en el detalle y especificación del derecho, especialmente en materia procedimental.

\section{Precariedad regulatoria general del derecho de acceso a la información por parte de los partidos}

$\mathrm{Al}$ adentrarnos en las regulaciones del derecho de acceso, tuvimos presente cómo cada normativa interna -en aquellos casos en que existe regulación al respecto- buscaba brindar garantías del derecho en términos cualitativos, esto es, cómo se estructura un procedimiento que habilite a sus afiliados obtener eficazmente la información solicitada y que las denegaciones de acceso se ajusten a derecho.

Frente a la omisión del legislador en establecer detalles mínimos a considerar en la regulación normativa interna de cada partido en relación con el procedimiento de ejercicio del derecho ${ }^{44}$, creemos que, a lo menos, se ha de tener a la vista, como modelo ideal de contraste, aquel procedimiento previsto por el legislador para el ejercicio del derecho de acceso a la información pública en la Ley de Transparencia ${ }^{45}$. Así, la normativa partidaria sería eficaz en brindar garantías mínimas que habiliten a sus afiliados el ejercicio de este derecho, si se observa, a lo menos, los siguientes elementos procedimentales: requisitos y formas de efectuar la solicitud de acceso a la información; plazo para respuesta de solicitud; reglas sobre costos de reproducción y entrega de información; derecho de oposición de terceros frente a información que pudiere afectarles y; finalmente, requisitos formales de la impugnación de la omisión de respuesta o la negativa de entrega de información ante el órgano contralor del partido, junto con su respectivo procedimiento de tramitación.

Basados en dicho criterio, se procedió a clasificar a la normativa interna de los partidos políticos en tres niveles de intensidad regulatoria: intensidades regulatorias baja, media y alta del procedimiento y ejercicio del derecho de acceso a la información por parte de sus afiliados. A continuación se explicará en qué consiste cada uno de estos niveles regulatorios y los respectivos partidos políticos que los componen ${ }^{46}$.

a) Intensidad regulatoria baja. En este nivel regulatorio se encuentran aquellos partidos políticos que se limitan a realizar una mera enunciación y reconocimiento del derecho de acceso a la información, o que si bien contienen algún tipo de regulación

44 Tampoco hubo mayor discusión en la tramitación legislativa de la Ley 20.915 que nos ilustrara acerca de este punto. Véase Biblioteca del Congreso Nacional, 2018, pp. 109;111.

${ }^{45}$ Véase los artículos 10 y siguientes de la Ley de transparencia de la función pública y de acceso a la información de la Administración del Estado, aprobada por el Artículo Primero de la Ley 20.285, sobre acceso a la información pública.

${ }^{46}$ Los documentos normativos de cada partido político en materia de acceso a la información, según su pertenencia a los distintos niveles regulatorios, y a la fecha de cierre del presente estudio, pueden ser consultados en el siguiente sitio web: https://www.dropbox.com/sh/cqbghlr30p8dto7/AACphmToOIudwGsH50jyOCja? $\mathrm{dl}=0$ [fecha de consulta: 27.02.2019]. 
más allá de su mera enunciación, dicha regulación no produce mayores efectos prácticos. En definitiva, se trata de normativas internas que repiten o reiteran lo dispuesto en la misma LOCPP.

Dentro de los partidos políticos que se limitan a realizar una mera enunciación del derecho, se posicionan los siguientes: PPD ${ }^{47}$, Federación Regionalista Verde Social ${ }^{48}$, Poder Ciudadano ${ }^{49}$ e Izquierda Anticapitalista de los Trabajadores ${ }^{50}$. Esta práctica regulatoria no aporta sustancialmente nada nuevo a lo establecido por el artículo $20 \mathrm{~N}^{\circ} 1$, letras f) y g) LOCPP, tornando dicha normación en superflua. Inclusive, en algunos casos, se reproducen en términos idénticos dichos preceptos legales ${ }^{51}$.

Dentro de los partidos políticos que contienen algún tipo de regulación por sobre la mera enunciación, pero sin producir mayores efectos prácticos, se encuentran: Partido Ecologista Verde y Partido Regionalista Independiente Demócrata. El primero de ellos reproduce en términos idénticos el artículo $20 \mathrm{~N}^{\circ} 1$, letras f) y g) LOCPP y, pese a que se contempla un procedimiento de denuncia al Tribunal Supremo, que es posible determinar aplicable en el caso en que al afiliado solicitante no se le entregue la información requerida (art. 30, letra j), no existe regulación del procedimiento por el que se solicita y se pudiere negar dicha información ${ }^{52}$. El segundo partido político, igual que el anterior, reproduce de manera idéntica el artículo $20 \mathrm{~N}^{\circ} 1$, letras f) y g) LOCPP y, si bien dispone de una regulación específica acerca de transparencia y publicidad de la información, aquella regulación únicamente tiene por objeto temas de transparencia activa y no de derecho de acceso a la información ${ }^{53}$.

El 35\% de los partidos políticos que cuentan con algún tipo de regulación en la materia objeto de este estudio pertenecen a esta categoría.

b) Intensidad regulatoria media. En este nivel regulatorio se encuentran aquellos partidos políticos que efectúan una enunciación y reconocimiento del derecho de acceso a la información, pero que, además, contemplan algún tipo de regulación de carácter más específico, y que genera efectos prácticos en su aplicación. Sin embargo, la adicional regulación tiene efectos de baja intensidad respecto de la habilitación y ejercicio del derecho de acceso, en el entendido de establecer solo alguno o algunos de los elementos procedimentales del modelo ideal propuesto, y que no permiten, en consecuencia, satisfacer del todo la eficacia en el ejercicio del derecho.

Dentro de este nivel se encuentran los siguientes partidos políticos: RN, Evópoli, UDI, PS, RD, Partido País Progresista, Más Izquierda Ciudadana y Partido Ciudadanos.

\footnotetext{
47 Véase Estatuto del PPD, de 9 de febrero de 2008 (art. $4^{\circ}$, letra d).

${ }^{48}$ Véase Estatuto de Federación Regionalista Verde Social, de 30 de marzo de 2018 (art. $3^{\circ}$, letras f) y g).

49 Véase Estatuto del Partido Poder, de 29 de abril de 2018 (art. 5º letra e).

${ }^{50}$ Véase Estatuto de Izquierda Anticapitalista de los Trabajadores, de 10 de enero de 2018 (art. $3^{\circ}$, letra d).

${ }^{51}$ Casos del PPD, UDI y Federación Regionalista Verde Social.

52 Véase Estatuto del Partido Ecologista Verde, de 16 de julio de 2018 (art. $3^{\circ}$, letras f) y g).

53 Véase Estatuto del Partido Regionalista Independiente Demócrata, de 20 de febrero de 2018 (art. $3^{\circ}$, letras f) y g) y arts. 48 y ss.).
} 
Entre las materias adicionales que son reguladas más allá de la mera enunciación o reconocimiento del derecho, se encuentran, por ejemplo, reglas de especificación que limitan el objeto de la solicitud ${ }^{54}$; reglas que extienden la titularidad de este derecho a sus adherentes, al establecer respecto de ellos el derecho a "ser informado(a) acerca de las políticas internas y externas del Partido, las finanzas, las licitaciones efectuadas con terceros, resoluciones de congresos o ampliados, etc. La información es un derecho irrenunciable de los y las militantes que el Partido reconoce [.... "55; reglas relativas a determinar quién soporta el costo de reproducción o entrega de cierto tipo de información solicitada ${ }^{56}$; atribuciones expresas del Tribunal Supremo de velar y garantizar el ejercicio de los derechos de los afiliados, incluidos los del artículo 20 LOCPP ${ }^{57}$; o reglas que establecen un plazo expreso para recurrir al Tribunal Supremo ante la negativa de entregar la información solicitada ${ }^{58}$.

Mención aparte requieren aquellos casos de una cantidad importante de partidos situados en este nivel regulatorio ( $57 \%$ de ellos) que, si bien cuentan con una regulación detallada de temas de información partidaria, lo hacen confundiendo el objeto de los deberes impuestos por la LOCPP. En todos estos casos se evidencian reglas que, bajo la denominación amplia respecto de materias de transparencia activa y acceso a la información, se limitan a regular en su mayoría las primeras ${ }^{59}$-cuestiones que ya se encuentran normadas por los artículos 49 y 50 LOCPP y la Instrucción General N 12 del Consejo para la Transparencia-. Inclusive, lejos de establecer un derecho de acceso a la información partidaria en términos amplios, restringen la información susceptible de

${ }^{54}$ Este es el caso de RN, que limita la información susceptible de ser solicitada y recibida a "las decisiones y acuerdos adoptados por los organismos del Partido". Véase Estatuto de RN, de 19 de marzo de 2016 (art. $5^{\circ}$, letra a).

55 Véase Estatuto del PS, de 10 de agosto de 2018 (art. $3^{\circ}$, letra c).

${ }^{56}$ Caso de RN, en que se permite al afiliado, "solicitar a su costa, a la Directiva Nacional del Partido o al Servicio Electoral, copia del registro de afiliados al que pertenece. [...] Los afiliados no podrán divulgar los datos personales del Registro ni utilizarlos con finalidades distintas del ejercicio de sus derechos como militantes" (art. $5^{\circ}$, letra $\mathrm{m}$ ) del estatuto partidario).

57 Véase Estatuto de Evópoli, de 1 de junio de 2015 (art. 40, letra j) y; Estatuto del Partido País Progresista, 30 de julio de 2018 (art. 38). Sin embargo, este tipo de regulación no es detallada, ni tampoco regula la fase anterior al reclamo por no entrega de la información solicitada, tales como órgano encargado de responder, plazos de respuesta, etc.

58 Caso de UDI (art. 6, letra f) del estatuto partidario).

59 Véase Estatuto de Evópoli, de 1 de junio de 2015 (arts. 48 y siguientes); Estatuto del Partido País Progresista, 30 de julio de 2018 (arts. 69 y 70); Estatuto del Partido Ciudadanos, de 25 de abril de 2018 (arts. 61 y 62); Estatuto de Más Izquierda Ciudadana, de 25 de abril de 2018 (art. 53); y Reglamento Orgánico Interno de RD, de octubre de 2015 (arts. 115 y siguientes). En el caso de RD, se ha de indicar que, según información proporcionada por el partido mediante correo electrónico, existiría un nuevo estatuto que se encontraría actualmente en revisión ante el Servel, y que consagraría en exactos términos lo dispuesto por el artículo $20 \mathrm{~N}^{\circ}$ 1, letra f) LOCPP, pasando a ser parte del nuevo reglamento interno del partido la regulación procedimental del derecho de acceso a la información partidaria. La respuesta de RD puede ser consultada en el siguiente sitio web: https://www.dropbox.com/sh/cqbghlr30p8dto7/AACphm'ToOIudwGsH50jy-0Cja?dl=0 [fecha de consulta: 27 de febrero de 2019]. 
ser solicitada por el afiliado a las resoluciones, procedimientos y sentencias del Tribunal Supremo como copias a las actas de las sesiones de sus órganos internos.

El $47 \%$ de los partidos políticos que cuentan con algún tipo de regulación en la materia pertenecen a esta categoría.

c) Intensidad regulatoria alta. En este nivel regulatorio se encuentran aquellos partidos políticos que regulan con un mayor grado de especificación y garantía, en términos procedimentales, el ejercicio del derecho, y generan las condiciones habilitantes para que sus afiliados accedan a la información. Es decir, cumplen con todos o gran parte de los elementos procedimentales del modelo ideal propuesto. Dentro de este nivel, se encuentran los siguientes partidos políticos: PDC, PC y Partido Radical Socialdemócrata.

El PDC, pese consagrar el derecho de acceso a la información en términos idénticos al artículo $20 \mathrm{~N}^{\circ}$ 1, letras f) y g) LOCCPP, al igual que el PS, extiende la titularidad de este derecho a sus adherentes ${ }^{60}$. Asimismo, se establece dentro de las facultades del Tribunal Supremo, la de velar y garantizar los derechos de sus afiliados del artículo 20 LOCPP ${ }^{61}$. Finalmente, según información brindada mediante correo electrónico, se informó que la solicitud de acceso a la información por parte de sus afiliados o adherentes debe ser enviada al Secretario Nacional vía correo electrónico o carta, detallando un aspecto procedimental clave del ejercicio del derecho ${ }^{62}$.

Respecto del PC, si bien reconoce en sus estatutos el derecho en términos exactos a la LOCPP, posteriormente regula el medio por el que se puede formular la solicitud de información, plazo de respuesta del partido para la entrega de la información, así como un plazo para recurrir ante el Tribunal Supremo ante la negativa de entrega de información ${ }^{63}$. Inclusive, prevé mediante su sitio web un formulario de solicitud de acceso a la información, debiendo el solicitante especificar el órgano partidario al que va dirigida, así como la existencia de un plazo para la entrega de información (20 días hábiles), pudiendo el partido solicitar una prórroga de este plazo (10 días, aunque sin especificar si son hábiles o no) ${ }^{64}$.

Finalmente, el caso del Partido Radical Socialdemócrata constituye el caso más destacable en esta materia. El partido tiene un Reglamento Especial de Solicitudes de Acceso a la Información (SAI) con diversas reglas que disciplinan el ejercicio del derecho, previendo la forma de efectuar la solicitud, la autoridad ante la que se ha de formular, plazos de respuesta, costos de reproducción asociados a la entrega de la información, entre otros elementos del procedimiento ${ }^{65}$.

${ }^{60}$ Véase Estatuto del PDC, de 5 de junio de 2017 (art. $3^{\circ}$ ).

61 Artículo 76, letra n) del estatuto partidario del PDC.

${ }^{62}$ La respuesta del PDC puede ser consultada en el siguiente sitio web: https://www.dropbox.com/sh/ cqbghlr30p8dto7/AACphmToOIudwGsH50jy-0Cja?dl=0 [fecha de consulta: 27.02.2019].

63 Véase Estatuto del PC, de 9 de octubre de 2018 (art. 11, letra f) y art. 13).

${ }^{64}$ El formulario de solicitud de acceso a la información del PC puede ser consultado en el siguiente sitio web: https:/www.dropbox.com/sh/cqbghlr30p8dto7/AACphmToOIudwGsH50jy-0Cja?dl=0 [fecha de consulta: 27.02.2019].

${ }^{65}$ Véase Reglamento de Solicitudes de Acceso a la Información del PRS, de 6 de abril de 2018. 
En este punto, es oportuno destacar que $18 \%$ de los partidos políticos que cuentan con algún tipo de regulación en la materia pertenecen a esta categoría.

\section{Balance de la revisión empírica}

La informalidad regulatoria es una práctica lamentable que caracteriza a los partidos políticos en cuanto no todos disponen de la existencia de sitio web-ya sea informado o no- para la publicación de la propia normativa partidaria -y de otros antecedentes- así como lo mandata el legislador; y en el caso de contar con aquello, no todos cumplen con el deber de transparencia activa que los obliga ${ }^{66}$. En lo que nos convoca, no todos los partidos políticos cuentan con una regulación del derecho de acceso a la información por parte de sus afiliados y, en el caso en que ello ocurre, los instrumentos normativos específicos que lo regulan, así como el nivel de intensidad regulatoria que adoptan son, en general, dispares. A modo de resumen, se presenta la siguiente tabla que sistematiza la información analizada.

Tabla 1. Clasificación de partidos políticos según existencia de sitio web, normativa partidaria publicada, regulación del derecho de acceso a la información y nivel de intensidad regulatoria

\begin{tabular}{lcccc}
\hline Partido político & $\begin{array}{c}\text { Existencia } \\
\text { de sitio web }\end{array}$ & $\begin{array}{c}\text { Publicación de } \\
\text { normativa } \\
\text { partidaria }\end{array}$ & $\begin{array}{c}\text { Regulación del } \\
\text { derecho de acceso } \\
\text { a la información }\end{array}$ & $\begin{array}{c}\text { Nivel } \\
\text { de intensidad } \\
\text { regulatoria }\end{array}$ \\
\hline DC & $\checkmark$ & $\checkmark$ & $\checkmark$ & Media \\
\hline PPD & $\checkmark$ & $\checkmark$ & $\checkmark$ & Alta \\
\hline UDI & $\checkmark$ & $\checkmark$ & $\checkmark$ & Baja \\
\hline PS & $\checkmark$ & $\checkmark$ & $\checkmark$ & Media \\
\hline PRS & $\checkmark$ & $\checkmark$ & $\checkmark$ & Media \\
\hline PC & $\checkmark$ & $\checkmark$ & $\checkmark$ & Alta \\
\hline PH & $\checkmark$ & $\checkmark$ & $\checkmark$ & Alta \\
\hline Andha Chile & $\checkmark$ & $\checkmark$ & $\times$ & N/A \\
\hline Evópoli & $\checkmark$ & $\checkmark$ & $\checkmark$ & Media \\
\hline RD & $\checkmark$ & $\checkmark$ & $\checkmark$ & Media \\
\hline
\end{tabular}

${ }^{66}$ Contreras (2018). 


\begin{tabular}{lcccc}
\hline Partido político & $\begin{array}{c}\text { Existencia } \\
\text { de sitio web }\end{array}$ & $\begin{array}{c}\text { Publicación de } \\
\text { normativa } \\
\text { partidaria }\end{array}$ & $\begin{array}{c}\text { Regulación del } \\
\text { derecho de acceso } \\
\text { a la información }\end{array}$ & $\begin{array}{c}\text { Nivel } \\
\text { de intensidad } \\
\text { regulatoria }\end{array}$ \\
\hline FRVS & $\checkmark$ & $\checkmark$ & $\checkmark$ & Baja \\
\hline IAT & $x$ & $x$ & $\checkmark$ & Baja \\
\hline Ciudadanos & $\checkmark$ & $\checkmark$ & $\checkmark$ & Media \\
\hline PRID & $\checkmark$ & $x$ & $\checkmark$ & Media \\
\hline PEV & $\checkmark$ & $\checkmark$ & $\checkmark$ & Baja \\
\hline Poder Ciudadano & $\checkmark$ & $\checkmark$ & $\checkmark$ & Baja \\
\hline Igualdad & $\checkmark$ & $\checkmark$ & $\checkmark$ & Baja \\
\hline MIC & $x$ & $\checkmark$ & $\checkmark$ & N/A \\
\hline
\end{tabular}

Fuente: elaboración propia.

La cantidad de partidos políticos que integran el nivel de intensidad regulatoria alta -y que importa, desde luego, el grado más óptimo de la regulación según el estándar normativo propuesto- es considerablemente inferior al total de partidos que cuentan con algún tipo de regulación en la materia. En otros términos, la cantidad de partidos políticos que se posicionan en el nivel bajo o medio de regulación es significativamente superior a la cantidad de partidos que se insertan en un nivel de regulación alta del derecho (82\% respecto del total). Lo anterior, puede ser ilustrado de mejor manera a partir del siguiente gráfico.

Gráfico 1. Porcentaje de partidos políticos según intensidad regulatoria del derecho de acceso a la información

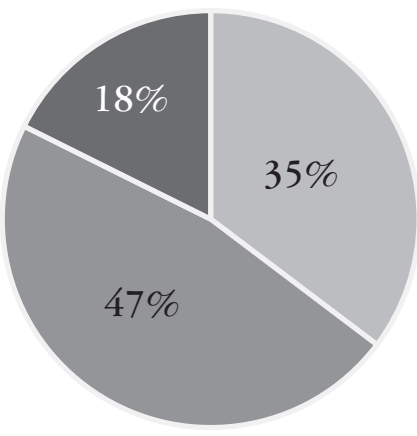

$$
\text { Intensidad baja Intensidad media }
$$

Intensidad alta

Fuente: elaboración propia. 
De la muestra estudiada, se estima que la mera repetición de la regla legal como técnica regulatoria partidaria, resulta superflua habida consideración de la existencia y aplicación directa del artículo $20 \mathrm{~N}^{\circ}$ 1, letras f) y g) LOCPP a nivel interno del partido político, práctica que permite preguntarse si acaso aquella constituye realmente un tipo de regulación como la que ordena el legislador.

Salvo pocas excepciones, es posible afirmar que, en general, en la práctica regulatoria interna de los partidos en el tema que nos convoca, no se establecen supuestos procedimentales mínimos para el ejercicio de este derecho, así como individualización del órgano encargado de entregar la información solicitada o comunicar su denegación, los plazos de entrega de la información, el mecanismo para notificar a terceros cuando la entrega de la información solicitada pudiere afectarles en sus derechos, los costos asociados a la reproducción y entrega de la información solicitada, o el procedimiento de impugnación ante el órgano contralor del partido, entre otras materias.

En los pocos casos regulatorios en que ello acontece, esta regulación, sin embargo, no se realiza de manera acabada. Al contrario, se efectúa de manera dispar por parte de los partidos políticos, en cuanto a las materias que aquí se evidencian. En efecto, solo uno de los 20 partidos políticos legalmente constituidos a la fecha de este estudio posee una regulación acabada en todas estas materias en cuanto al procedimiento del ejercicio del derecho de acceso a la información por parte de sus afiliados (Partido Radical Socialdemócrata).

En cuanto a la regulación del objeto del derecho, esto es, la información que puede ser solicitada por los afiliados a partidos, estimamos que por aplicación supletoria de la LOCPP y el artículo $8^{\circ}$ de la Constitución $-\mathrm{y}$ su respectiva adecuación a materias político-partidarias-, la falta de regulación interna puede ser reconducida a estas disposiciones. El mismo criterio aplicaría para la regulación de las causales de secreto o reserva a las que puede estar afecta la entrega o denegación de información solicitada.

De lo anterior, es posible colegir que, en la práctica, la autonomía que el legislador entrega a los partidos políticos en materia de regulación del derecho de acceso a la información, por parte de sus afiliados, impacta en la intensidad normativa que habilita el ejercicio del derecho.

\section{COnClusiones}

La reforma a la LOCPP mediante la Ley 20.915, introdujo el derecho de acceso a la información de los partidos políticos para sus afiliados. Se trató de un cambio dentro de un contexto de reformas más amplias para fortalecer los mecanismos de rendición de cuentas de estas entidades, esenciales para nuestra democracia, como contrapartida a las medidas de fortalecimiento institucional y asignación de recursos públicos para las tareas que le son confiadas por el legislador.

Sin embargo, el legislador se encargó de establecer este nuevo derecho, sin desarrollarlo en términos procedimentales. De esta forma, se observa una omisión de una serie de reglas que sí se encuentran en la Ley de Transparencia -respecto de los órganos 
de la Administración del Estado- y que hacen viable el ejercicio del derecho de acceso a la información. En este caso, la ley reserva a los partidos políticos un ámbito de competencia por el que les otorga autonomía para regular internamente cómo se ejerce este derecho por parte de sus afiliados.

En la revisión que hemos efectuado a la normativa de los partidos legalmente constituidos a la fecha del presente estudio, hemos logrado verificar que existen importantes brechas y deficiencias regulatorias que posiblemente obstaculizarán el ejercicio del derecho. En varios casos existe una mera repetición de las disposiciones legales, sin mayores detalles regulatorios, y que nada aportan a la configuración interna del derecho. Esta práctica permite preguntarse si acaso aquella constituye realmente un tipo de regulación como la que ordena el legislador. Solo en una minoría de partidos políticos - menos de un quinto de ellos- existen instrumentos normativos que detallan cuestiones de titularidad, forma de ejercicio, autoridad responsable, u otros aspectos procedimentales. Sin embargo, cuestiones cruciales para el correcto ejercicio del derecho -como las reglas respecto de plazos, notificaciones a terceros o el procedimiento de impugnación de la decisión denegatoria de acceso- son derechamente omitidas.

Como lo planteamos en la introducción, en este caso se demuestra que la remisión que hace la ley a los partidos favorece la autonomía partidaria en desmedro de la protección de un derecho de los afiliados que buscaba ser central en el nuevo gobierno y rendición de cuentas de los partidos políticos. La técnica legislativa de confiar en los partidos para regular ciertas cosas de forma autónoma debe ser revisada críticamente, a la luz de los resultados de este caso de estudio. La ausencia de reglas básicas, por parte de los partidos, terminan configurando un derecho pauperizado. La práctica y las eventuales reclamaciones ante el Servel, y su consecuente jurisprudencia administrativa, permitirán verificar en qué medida el derecho es efectivamente tutelado ante los partidos políticos.

Antes de confiar en que el statu quo cambiará espontáneamente, algunas alternativas pueden ser planteadas. En primer término, siempre es posible reformar la remisión que hace hoy el legislador a los partidos y definir los contenidos básicos del derecho y su procedimiento en la misma ley. Otras alternativas menos intensas suponen la acción del regulador. Servel, por ejemplo, podría proveer una "ley marco" o "estatutos marco" que fijen un procedimiento con los factores mínimos para regular adecuadamente el derecho de acceso a la información. Finalmente, si el Servel no toma la iniciativa, la sociedad puede aportar con modelos o ejemplos regulatorios que permitan a los partidos orientar su acción y modificar sus estatutos. En cualquier caso, es claro que los partidos políticos, por sí solos, se encuentran en deuda en la protección del derecho de acceso a la información de sus afiliados.

\section{BiBLIOGRAFÍA}

Aldunate, Eduardo, 2008: Derechos Fundamentales, Santiago de Chile Legal Publishing. Aldunate, Eduardo, 2009: Constitución Política de la República de Chile. Doctrina y Jurisprudencia, Tomo I, Santiago, Thomson Reuters. 
Amunátegui, Gabriel, 1952: Partidos Políticos, Santiago, Editorial Jurídica de Chile.

Barros, Enrique, 1984: “Aspectos Jurídicos del Estatuto de los Partidos Políticos”, en Estudios Públicos, Centro de Estudios Públicos, No 14.

Biblioteca del Congreso Nacional, 2018: Historia de la Ley No 20.915, 15 de abril de 2016. Disponible en : https://www.bcn.cl/historiadelaley/fileadmin/file_ley/4920/HLD_4920_3 7a6259cc0c1dae299a7866489dff0bd.pdf [fecha de consulta: 29.09.2018].

Contreras, Pablo, 2018: "Partidos Políticos y Transparencia", en Anuario de Derecho Público UDP, Santiago, Ediciones UDP.

Díaz, Francisco y Sierra, Lucas, 2012: Propuesta de Reformas a los Partidos Políticos en Chile, Santiago, CEP/CIEPLAN.

Fernández, Miguel Ángel, 2005: "El Principio de Publicidad de los Actos Estatales en el nuevo Artículo $8^{\circ}$ Inciso $2^{\circ}$ de la Constitución”, en Zúñiga, Francisco, Reforma Constitucional, Santiago, Lexis Nexis.

Fernández, Miguel Ángel, 2007: "El Principio Constitucional de Publicidad”, en Revista de Derecho Público, Universidad de Chile, Vol. 69, T. I.

Ferrada, Juan Carlos, 2010: "El Ámbito de Aplicación de la Ley de Transparencia. La Exclusión Parcial de Órganos Estatales y Administrativos de la Aplicación del Régimen General”, en Letelier, Raúl y Rajevic, Enrique (coords.), Transparencia en la Administración Pública, Santiago, LegalPublishing.

García, Ana María, 1988: Ley Orgánica Constitucional de Partidos Político. Historia de su Establecimiento y Debate Doctrinario, Santiago, Editorial Jurídica de Chile.

García, Ana María, 2017: "Partidos Políticos y Modificaciones Introducidas por la Ley Orgánica Consittucional No 20.915 de 2016", en Asociación Chilena de Derecho Constitucional, Teoría Política y Constitucional. Libro Homenaje al Profesor Ismael Bustos Concha, Santiago, Editorial Jurídica de Chile.

Hernández, Domingo, 2006: "Notas sobre Algunos Aspectos de la Reforma a las Bases de la Institucionalidad, en la Reforma Constitucional de 2005: Regionalización, Probidad y Publicidad de los Actos", en Nogueira, Humberto (coord.), La Constitución Reformada de 2005, Santiago, Librotecnia.

Jordán, Tomás y Figueroa, Pamela, 2017: "La Ruta hacia una Mejor Democracia”, en Ministerio Secretaría General de la Presidencia e IDEA, Reformas Políticas en Chile 2014-2016. Análisis y Evaluación de las Modificaciones al Sistema Político Chileno durante el Gobierno de la Presidenta Michelle Bachelet, Santiago, Ministerio Secretaría General de la Presidencia. Disponible en: https://www.unaconstitucionparachile.cl/informe_reformas_politicas_en_chile_2014-2016. pdf [fecha de consulta: 29.09.2018].

Nogueira, Humberto, 2005: "El Rol de los Partidos Políticos en las Constituciones de América Latina en la Alborada del Siglo XXI", en Estudios Constitucionales, Vol. 3, No 2.

Osonio, Gabriel, 2018: Partidos Políticos. Historia Institucional y Dogmática Jurídica, Santiago, Editorial Hammurabi.

Oñate, Pablo, 2005: "Los Partidos Políticos", en Del Águila, Rafael (ed.), Manual de Ciencia Política, Madrid, Trotta.

Pérez Royo, Javier, 2007: Curso de Derecho Constitucional, Madrid, Marcial Pons.

Ribera, Teodoro, 2008: "Estatuto Jurídico de los Partidos Políticos en Chile. Veinte Años de la Ley Orgánica Constitucional de los Partidos Políticos”, en Fontaine, Arturo; Larroulet, Cristián; Navarrete, Jorge y Walker, Ignacio (coord.), Reforma de los Partidos Políticos en Chile, Santiago, PNUD, CEP, Libertad y Desarrollo, Proyectamérica y CIEPLAN.

Rojas, Christian, 2014: 'La Categoría Jurídica de los 'Servicios Privados de Interés Público'. El Caso de las Juntas de Vigilancia de Ríos”, en Revista Chilena de Derecho, Vol. 41, No 1. 
Ruiz-Tagle, Pablo, 2006: "Los Derechos Fundamentales ante la Reforma del 2005”, en Revista de Derecho Público, Universidad de Chile, Vol. 68.

Santibáñez, Francisco, 2014: "Sistema de Gobierno y Partidos Políticos en Chile: Paradojas de Nuestra Democracia”, en Asociación Chilena de Derecho Constitucional, Gobierno. Presidente de la República. Libro Homenaje al Profesor Hernán Molina Guaita, Santiago, Editorial Jurídica de Chile.

Servicio Electoral, 2018: Partidos Constituidos. Disponible en: https://servel.cl/partidosconstituidos/ [fecha de consulta: 20.08.2018].

Silva Bascuñán, Alejandro, 1963: Tratado de Derecho Constitucional, Tomo III, Vol. 2, Santiago, Editorial Jurídica de Chile.

Silva Gallinato, María Pía, 2016: "El Control del Financiamiento de los Partidos y de las Campañas Electorales: La evolución de su Regulación en Chile”, en Revista de Derecho, Universidad Finis Terrae, Año VI, Nº 2 .

Soто KLOss, Eduardo, 1986: "La organización de la Administración del Estado. Un complejo de personas jurídicas", en Gaceta Jurídica, N $\mathrm{N}^{\circ} 73$.

Verdugo, Mario y García, Ana María, 1992: Manual de Derecho Político: Las Fuerzas Políticas y los Regímenes Políticos, Tomo II, Santiago, Editorial Jurídica de Chile.

Normas jurídicas citadas

Constitución Política de la República de Chile. Diario Oficial, 22 de septiembre de 2005.

LEY N 20.285, sobre Acceso a la Información Pública, que aprueba la Ley de Transparencia de la Función Pública y de Acceso a la Información de la Administración del Estado. Diario Oficial, 20 de agosto de 2008.

Decreto con Fuerza de Ley $\mathrm{N}^{\circ}$ 4, que fija el texto refundido, coordinado y sistematizado de la Ley $N^{\circ}$ 18.603, Orgánica Constitucional de Partidos Políticos. Diario Oficial, 6 de septiembre de 2017 .

\section{Jurisprudencia citada}

Corte de Apelaciones de Valparaíso, 14.06.2010, Rol No 2361-2009.

DE Apelaciones de Valparaíso, 29.06.2010, Rol No 294-2010.

Corte de Apelaciones de Santiago, 10.08.2010, Rol No 132-2010.

Corte de Apelaciones de Puerto Montt, 27.01.2011, Rol No 395-2010.

Corte de Apelaciones de Puerto Montt, 13.02.2012, Rol No 906-2011.

Corte de Apelaciones de Iquique, 01.06.2015, Rol No 195-2015.

CorTe Suprema, 30.07.2015, Rol No 7517-2015. 